DOI: 10.12731/2658-6649-2019-11-5-58-63

УДК 616.995.122

\title{
БИОХИМИЧЕСКИЕ ПОКАЗАТЕЛИ МЕТАБОЛИЧЕСКИХ ПРОЦЕССОВ У БОЛЬНЫХ ХРОНИЧЕСКИМ ОПИСТОРХОЗОМ С НАЛИЧИЕМ ГЕНЕТИЧЕСКИХ ПОЛИМОРФИЗМОВ, АССОЦИИРОВАННЫХ С ПРЕДРАСПОЛОЖЕННОСТЬЮ К РАЗВИТИЮ ОСТЕОПОРОЗА
}

\author{
Косырева А.Н., Бакитановская И.В., Степанова Т.Ф., \\ Степанова К.Б., Зматракова Е.А., Ожирельева И.В.
}

Проведено сопоставление биохимических показателей основных обменных прочессов и функиий печени в подгруппах больных описторхозом, вызванным Opisthorchis felineus, с наличием и отсутствием мутаций в локусах, ассочиированных с предрасположенностью к остеопорозу.

Ключевые слова: генетический полиморфизм; остеопороз; хронический описторхоз; биохимические показатели; аллель.

\section{METABOLIC BIOCHEMICAL PARAMETERS \\ IN CHRONIC OPISTHORCHIASIS PATIENTS \\ WITH GENETIC POLYMORPHISMS ASSOCIATED WITH OSTEOPOROSIS SUSCEPTIBILITY}

\author{
Kosyreva A.N., Bakshtanovskaya I.V., Stepanova T.F., \\ Zmatrakova E.A., Ozhirelyeva I.V.
}

A comparison of the biochemical parameters of the main metabolic processes and liver functions in subgroups of patients with opisthorchiasis caused by Opisthorchis felineus, with the presence and absence of mutations in loci associated with a predisposition to osteoporosis, was made.

Keywords: genetic polymorphism; osteoporosis; chronic opisthorchiasis; biochemical indicators; allele. 


\section{Введение}

По данным ВО3, остеопороз занимает 4 место по распространенности среди неинфекционных заболеваний; в России он выявляется у $33,8 \%$ женщин и 26,9\% мужчин старше 50 лет - это около 10\% населения страны [1]. Метаболизм костной ткани зависит от поступления в организм кальция и витамина $\mathrm{D}$, других минеральных веществ и от уровней паратгормона, гормона роста, кальцитонина, эстрогена $($ ( $)$ и иестостерона $\left({ }^{\Uparrow}\right)$.

Полиморфные варианты рецептора к ЛПНП связаны с нарушением передачи сигналов системой Wnt и тем самым влияют на метаболизм остеобластов во время остеогенеза, связаны с минеральной плотностью кости и с предрасположенностью к остеопорозу [2]. Лактозная непереносимость является одной из причин развития остеопороза; что среди женщин-горожанок старше 45 лет непереносимость молока встречается с частотой 25-34\% [3]. Из-за связанных с этим изменений в метаболизме кальция, люди с генетической предрасположенностью к непереносимости лактозы чаще подвержены риску снижения костной массы [4].

Целью настоящего исследования являлось выявление влияния наличия или отсутствия генетической предрасположенности к развитию остеопороза на реакцию биохимических показателей основных обменных процессов и функций печени у больных с хронической описторхозной инвазией.

\section{Материалы и методы исследования}

Проведено исследование образцов крови 22 жителей г. Тюмени - 19 женщин и 3 мужчин (средний возраст 50 лет), с установленным диагнозом хронического описторхоза, проходивших патогенетическое и этиотропное лечение в клинике ФБУН ТНИИКИП Роспотребнадзора. Биохимические исследования проводили до начала лечения и через неделю после специфической антигельминтной терапии бильтрицидом.

Определяли в сыворотке крови активность аспартатаминотрансферазы (АСТ), аланинаминотрансеразы (АЛТ), гамма-глутамилтансферазы (ГГТ), щелочной фосфатазы (ЩФ) и $\alpha$-амилазы, концентрации общего билирубина, глюкозы и холестерина биохимическими методами с использованием коммерческих наборов реагентов. Выделение тотальной ДНК человека из образцов крови проводили с использованием зарегистрированных коммерческих наборов; выявление генетических полиморфизмов - методом пиросеквенирования с применением системы генетического анализа PyroMark24 и коммерческого набора реагентов «ОСТЕО-скрин» для выявления полиморфизмов в локусах: COL1 A1 = Коллаген тип 1 
IVS1 2046 G>T (rs1800012); ESR1 = Эстрогеновый рецептор T>C (Pvull) (rs2234693); ESR1 = Эстрогеновый рецептор A>G (Xbal) (rs9340799); LCT = Лактаза -13910 C>T (rs4988235); LRP5 = Рецептор к липопротеинам низкой плотности (ЛПНП) A1330V C > T (rs3736228); VDR = Рецептор к витамину D G>A (Bsml) (rs1544410). Статистическую обработку результатов проводили с использованием Т-критерия Стьюдента.

\section{Результаты исследования}

Среди обследованных больных описторхозом выявленные частоты встречаемости минорных аллелей по исследованным полиморфизмам в целом соответствуют литературным данным для европейских популяций, за исключением редкого аллеля в гене лактазы: его частота в группе обследованных в два раза выше. Не выявлено достоверных различий по значениям исследованных биохимических показателей между группами больных описторхозом с разными генотипами по полиморфным локусам COL1 A1 (rs1800012) и ESR1 (rs2234693; rs9340799). Активность АСТ, $\alpha$-амилазы и уровень общего билирубина достоверно не изменялись после антигельминтной терапии во всех исследованных подгруппах больных. Содержание глюкозы достоверно выше после лечения практически во всех подгруппах, возможно, из-за проведения патогенетической терапии.

В группе больных описторхозом с наличием мутантного аллеля С полиморфизма в гене лактазы обнаружены более низкие (характерные для здоровых людей) значения активности ГГТ до и после терапии и уровня холестерина после лечения. Наличие аллеля $\mathrm{C}$ обеспечивает сохранение нормального переваривания лактозы с возрастом - вероятно, это в некоторой степени противодействует вызванным инвазией нарушениям желчеотделения.

В группе с мутантным аллелем гена LRP5 обнаружена достоверно более низкая (близкая к норме) активность АЛТ и ЩФ до и после лечения, такой «протективный» эффект может быть связан с вовлечением рецептора ЛПНП в различные системы эндокринной регуляции, в том числе, в метаболизм холестерина [5].

При наличии мутации в гене VDR активность ЩФ была достоверно выше, чем в группе без мутации, возможно, нарушение функции данного рецептора взаимодействует с влиянием инвазии на указанный показатель, как и в случае с хроническим гепатитом $\mathrm{C}$ - при нем полиморфизмы гена VDR ассоциировались с большей степенью и быстрой прогрессией фиброза печени [6]. 


\section{Обсуждение}

Данные литературы и полученные результаты позволяют предполагать вовлечение исследованных генетических полиморфизмов, участвующих в регуляции метаболических процессов, в патогенетические механизмы и клинические проявления описторхозной инвазии.

\section{Заключение}

Многолетние исследования сотрудников ФБУН ТНИКИИП Роспотребнадзора позволили подробно описать иммунные реакции и состояние гепатобилиарной системы на разных стадиях описторхозной инвазии и в динамике терапии [7-9]. Обнаружение влияния полиморфных генов на показатели метаболических процессов у больных хроническим описторхозом может способствовать выявлению маркеров предрасположенности к реализации определенной клинической формы заболевания при заражении возбудителем описторхоза.

\section{Сиисок литературы}

1. https://www.who.ru (дата обращения: 04.04.2015).

2. Balemans W., Van Hul W. The genetics of low-density lipoprotein receptor-related protein 5 in bone: a story of extremes // Endocrinology. 2007; 148 (6): 2622-9.

3. Торопцова Н.В., Никитинская О.А., Беневоленская Л.И. Профилактика первичного остеопороза с помощью различных препаратов кальция // Научно-практическая ревматология. 2005; 1: 36-39.

4. http://пинни.pф/osteoporosis.html (дата обращения: 19.03.2019).

5. Jiang X.Y., Chen Y., Xu L., Li X., Cao F.F., Li L., Lu M., Jin L., Wang X.F. Association of LPR5 polymorphism with bone mass density and cholesterol level in population of Chinese Han. // Exp. Clin. Endocrinol. Diabetes. 2010 Jun;118(6):388-91.

6. Scalioni L.P., Santos B.R.D., Spritzer P.M., Villela-Nogueira C.A., Laura Lewis-Ximenez L., Pollo-Flores P., Bordalo Cathala Esberard E., Brandao-Mello C.E., Lampe E., Villar L.M. Impact of vitamin D receptor and binding protein gene polymorphisms in clinical and laboratory data of $\mathrm{HCV}$ patients: Cross sectional study. //Medicine (Baltimore). 2018 Feb;97(8).

7. Бакштановская И.В., Степанова Т.Ф. Анализ комплекса биохимических показателей функций печени при хроническом описторхозе. // Мед. паразитология и паразитар. болезни. 2005. № 4. С. 18-21.

8. Кальгина Г.А., Степанова Т.Ф. Значение цитокинов в иммунитете при описторхозе. // Мед.паразитол. паразитар.болезни. 2011. № 4. С. 49-54. 
9. Степанова Т.Ф. Описторхоз: новые взгляды на инвазионную болезнь, основы клинической реабилитации, методологию крупномасштабных оздоровительных работ // Тюмень: Изд-во ТюмГУ. 2002. 196 с.

\section{References}

1. https://www.who.ru (дата обращения: 04.04.2015).

2. Balemans W., Van Hul W. The genetics of low-density lipoprotein receptor-related protein 5 in bone: a story of extremes // Endocrinology. 2007; 148 (6): 2622-9.

3. Toroptsova N.V., Nikitinskaya O.A., Benevolenskaya L.I. [Prevention of primary osteoporosis with the help of various calcium preparations]. Scientific-practical rheumatology, 2005, №1, pp. 36-39.

4. http://пинни.pф/osteoporosis.html (дата обращения: 19.03.2019).

5. Jiang X.Y., Chen Y., Xu L., Li X., Cao F.F., Li L., Lu M., Jin L., Wang X.F. Association of LPR5 polymorphism with bone mass density and cholesterol level in population of Chinese Han. // Exp. Clin. Endocrinol. Diabetes. 2010 Jun;118(6):388-91.

6. Scalioni L.P., Santos B.R.D., Spritzer P.M., Villela-Nogueira C.A., Laura LewisXimenez L., Pollo-Flores P., Bordalo Cathala Esberard E., Brandao-Mello C.E., Lampe E., Villar L.M. Impact of vitamin D receptor and binding protein gene polymorphisms in clinical and laboratory data of $\mathrm{HCV}$ patients: Cross sectional study. //Medicine (Baltimore). 2018 Feb;97(8).

7. Bakshtanovskaya I.V., Stepanova T.F. [Analysis of the complex of biochemical indicators of liver function in chronic opisthorchiasis]. Medical parasitol. parasitic diseases, 2005, № 4, pp. 18-21.

8. Kalgina G.A., Stepanova T.F. [The value of cytokines in immunity with opisthorchiasis]. Medical parasitol. parasitic diseases, 2011, № 4, pp. 49-54.

9. Stepanova T.F. [Opisthorchiasis: New Views on Invasive Disease, Basics of Clinical Rehabilitation, Methodology for Large-Scale Health Improvement]. Tyumen: Publishing House of Tyumen State University, 2002, 196 p.

\section{ДАННЫЕ ОБ АВТОРАХ}

Косырева Анастасия Николаевна, младший научный сотрудник

Бакштановская Ирина Владимировна, ученый секретарь, кандидат биологических наук

Степанова Татьяна Федоровна, директор ТНИИКИП, доктор медицинских наук, профессор

Степанова Ксения Борисовна, ведущий научный сотрудник, кандидат медицинских наук 
Зматракова Елена Александровна, биолог

Ожирельева Ирина Владимировна, биолог

Федеральное бюджетное учреждение науки «Тюменский научно-исследовательский институт краевой инфекционной патологии» Роспотребнадзора

ул. Республики, 147, г. Тюмень, 625026, Российская Федерация info@tniikip.rospotrebnadzor.ru

DATA ABOUT THE AUTHORS

Kosyreva Anastasyia Nikolaevna, Junior Researcher

Bakshtanovskaya Irina Vladimirovna, Scientific Secretary, Candidate of Biological Sciences

Stepanova Tatyana Fedorovna, Director, Doctor of Medical Sciences, Professor

Stepanova Ksenia Borisovna, Leading Researcher, Candidate of Medical Sciences

Zmatrakova Elena Alexandrovna, biologist

Ozhirelieva Irina Vladimirovna, biologist

Tyumen Research Institute of Regional Infectious Pathology

Republican Street, 147, Tyumen, 625026, Russian Federation

info@tniikip.rospotrebnadzor.ru 